\title{
Factors Influencing Declining Voter Turnout - A Case Study in Neu-Ulm
}

\author{
Anton Bullinger ${ }^{1}$, Alexander Prosser ${ }^{2}$ \\ and Birgit Schenk ${ }^{3}$
}

\begin{abstract}
This paper is a continuation of a contribution published [1] by the same authors analysing possible reasons for low voter turnout in the City of Neu-Ulm. This paper operated under the limitation that only summary voter participation data from past elections was available which could be matched with demographic data from the city constituencies. Data that could be used to derive individual motivation was not available. To remedy this limitation, a questionnaire was sent to 3,000 inhabitants of Neu-Ulm to relate their voter participation to several possible factors influencing the propensity to vote and to derive recommendations for the City Council how to improve on voter participation in future elections. This contribution presents some preliminary results from the study.
\end{abstract}

\section{Introduction}

\subsection{The Issue}

Over the past years voter participation in Neu-Ulm has dropped in a dismal way, where in the last municipal election, only $37.9 \%$ participated as compared to $67.9 \%$ in the last federal election 2013[1]. In the past municipal elections, turnout has been monotonously falling in all city constituencies. The city administration was alerted to this and commissioned a study to analyse the dropping turnout against certain demographic properties in the constituencies. The linkage between the demographic properties and the fact whether a person voted or not would have been available in the voter roll but could not be analysed due to legal constraints. Only a summary analysis could be performed broken down by the 12 constituencies in the city.

The main results were that (i) age had no influence on turnout, (ii) the share of second residences had no influence ${ }^{4}$, (iii) the share of foreigners (EU and non-EU) had a negative correlation with turnout, however cannot have been the decisive factor, as only $1 / 6^{\text {th }}$ of Neu-Ulm's population is foreigners (half of them EU foreigners who are eligible to vote), (iv) duration of residence of Germans which shows a strong correlation between average duration of residence in a constituency and its turnout. However, only summary data of the municipal constituencies was available, no information on individual motivation.

\footnotetext{
${ }^{1}$ City of Neu-Ulm, Augsburger Str. 15, D-89231 Neu-Ulm

${ }^{2}$ University of Economics and Business, Vienna, Welthandelsplatz 1, A-1020 Vienna

${ }^{3}$ University of Public Administration and Finance, Reuteallee 36, D-71634 Ludwigsburg

${ }^{4}$ Holders of second residences are not allowed to vote in the municipal election, but a large share of them in a district could lead to alienation, bedroom-town effects etc. and thereby negatively impact turnout. This was however not observed.
} 


\subsection{Extended Study}

To remedy this fundamental limitation, a questionnaire was sent to 3,000 (main or secondary) residents of Neu-Ulm who were randomly selected (see Annex, questionnaire in German). 917 questionnaires were returned, which is a rather high percentage, almost one third. [2] As only a subproportionally small group of secondary residents answered the questionnaire $(1.7 \%$ as compared to $4 \%$ secondary residencies), they were excluded; 103 respondents did not answer the question $(11.2 \%)$; hence only the main resident respondents, that is 798 or $87 \%$ of all respondents, were included in the analysis.

The distribution of questionnaires over the city districts (ie, constituencies) significantly deviated from the distribution of the population in that larger districts had a relatively lower return rate than smaller, rurally structured districts - not a completely unexpected effect (cf. Figure 1). Concerning age, the same effect was observed, elderly respondents were significantly overrepresented in the sample (see Figure 2).

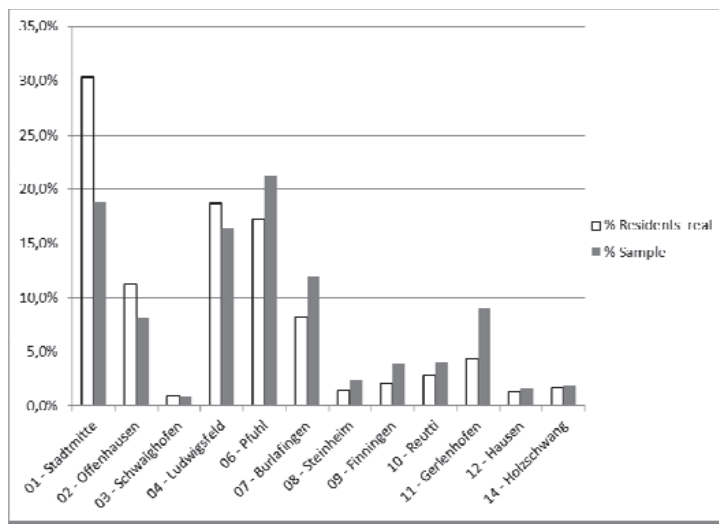

Figure 1: Distribution of residents real (main residencies only) and in the sample, X2 test significant on $99 \%$ level.

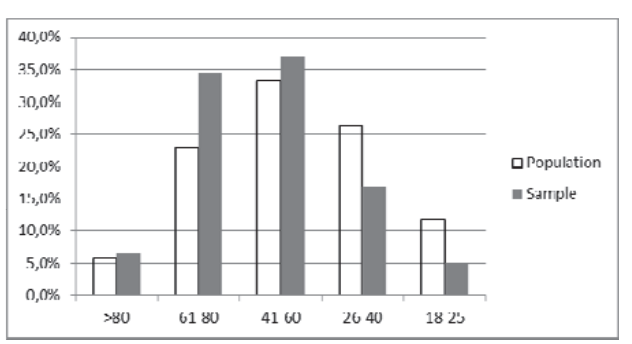

Figure 2: Distribution of age groups in the population and in the sample, $\mathrm{X} 2$ test significant on $99 \%$ level.

The largest bias in the sample, however, concerned the foreign respondents: Out of the 798 respondents who indicated a main residence in Neu-Ulm, only 27 did not have German citizenship. Altogether, there are $16.8 \%$ foreigners in the city (EU or non-EU) [1], but only $3.4 \%$ of the respondents belonged to that group. This already in itself leads to the first result of the study: The foreign population (EU or non-EU) is clearly not integrated/integrating into the political life of the municipality. Since the number of foreign respondents is so low and any results specifically derived within this group would be at the borderline of statistical validity, the empirical analysis in the following section will not distinguish between foreign and German population; however, in some case, X2 tests are performed between foreign and German respondents. In all analyses, the bias towards the smaller suburbs and towards older age groups has to be borne in mind.

This is the background of the study presented herein. The issue of declining voter turnout is a general one, the detailed data available for Neu-Ulm may hence serve to shed some light on the general problem beyond the case of application. The following section therefore introduces this more general topic. Sections 3 and 4 are then dedicated to a more detailed analysis of the questionnaire data. 


\section{Motivation to Vote}

\subsection{Explanatory Views}

There are several models in the literature to explain civic engagement, which can be seen as the superset of voter participation. Verba et al. [3] introduce a resource-based view: They introduce time, money (cf. pp. 288ff) and "civic skill"5 (cf. pp. 304ff) as resources for participation. Using empirical evidence they conclude that civic skills heavily depend on education, which is not evenly distributed in the population. ${ }^{6}$ They also compare skills required in a professional environment (giving presentations, formulating memos etc.) to skills needed in civic engagement, whether "conventional" or "unconventional" (following Barnes and Kasse [4]), such as (today's) social media, whereas unconventional may also refer to protests, boycotts etc [5]. A factor that may have a tendency to be underrated may be the skill to speak the language of the country of residence (and participation), which particularly applies to new immigrants as is pointed out by van Tubergen and Kalmijn [6]. However, Verba et al. focus on civic engagement in deliberative or consultative processes, it is difficult to see how these factors would influence voter turnout. The factor "time" (ultimately amounting to availability in this context) as advanced by Verba et al. however, could be important and will be tested against the data (see Questions 3.5 to 3.8 concerning postal voting, whether the polling station could be reached easily and whether respondents had time on election day).

Rosenstone and Hansen [7] offer an alternative model of voter participation ${ }^{7}$, that of voter mobilisation. In this view, turnout decreases if voters do not feel their voice makes a difference or voters do not identify themselves with the entity that is conducting the election (eg, the region or municipality they live in). Summarizing (p. 228), they conclude that apart from the availability of resources, mobilisation is key to turnout. Mobilisation in turn works through (i) loyalty to parties or individual candidates, (ii) issues or (iii) opportunities perceived by the electorate.

These sources in the literature offer a comprehensive model for explaining voter turnout; however, a factor that is clearly decisive for the Neu-Ulm case does not feature prominently - migration and the resulting high "turnover" in the population, which appeared to be the decisive factor in the summary study in [1].

\subsection{Identification with the City}

Questions $1.5-1.8$ were intended to check the degree to which the respondent identified with the home city. Question 1.5 ( $\mathrm{n}=651$ respondents) enquired about the intention to leave the city within the next five years. Only 5.6\% answered in the affirmative, which appears rather low. However, $19.7 \%$ did not respond, leaving the question open. Only considering those who moved to Neu-Ulm 2007 or later (using Question 1.3, $\mathrm{n}=123 / 651$ respondents) however showed 17.1\% answering in the affirmative and $30.9 \%$ abstaining, only $52 \%$ out of that group did not voice an intention to move

\footnotetext{
${ }^{5}$ Defined as ,the communications and organizational abilities that allow citizens to use time and money effectively in political life" (p. 304).

${ }^{6}$ They use their own tests for measuring language skills and relate it to the - heavily slanted - formal education levels of three population groups, Anglo-Whites, African Americans and Latinos. In contrast, the distribution between men and women is almost equal both in education levels and language skills (cf. Table 11.1 in [3]).

${ }^{7}$ They also stress the availability of time and resources (cf. p.12ff and - specific to elections - p. 133ff) stringently arguing via the onerous voter registration process in the U.S. (p. 230), but attach more importance to mobilisation effects asking themselves what mobilises an electorate.
} 
from Neu-Ulm within the next five years. This would confirm the result of the analysis in [1] which came to a similar conclusion based on summary data.

Question 1.8 enquired about whether Neu-Ulm residents spent their work time in Neu-Ulm (only $30.1 \%)^{8}$, their leisure time during the week $(84.6 \%)$ and at the weekend $(65.8 \%)$. This gives a remarkable picture in that the activity spread rather resembles a bedroom town, where people live and spend their leisure time but work somewhere else. This result is surprising because Neu-Ulm does have a university and several higher education institutions as well as a number of important employers. No indication was collected as to where respondents work but one can surmise that a substantial number of those $69.9 \%$ of the respondents who do not work in Neu-Ulm work in the neighbouring city of Ulm.

A key question was the identification with the city (Question 1.7, "I feel at home in my quarter, 6point Likert scale). The distribution of responses is shown in Figure 3, three quarters of the respondents (values 1 and 2 on the scale) feel at home in Neu-Ulm. There is no significant difference in answers from German and non-German respondents. ${ }^{9}$

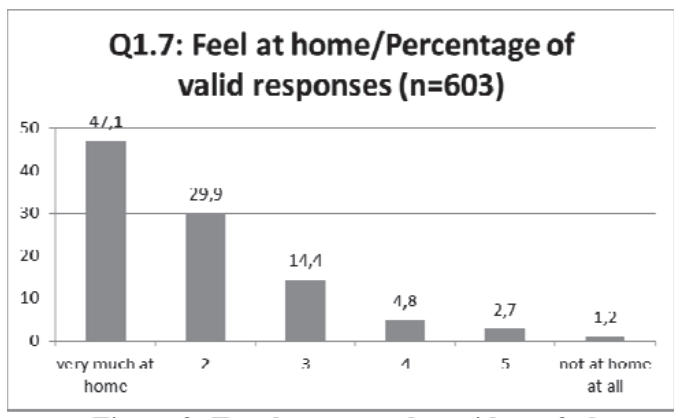

Figure 3: To what extent do residents feel at home in their quarter?

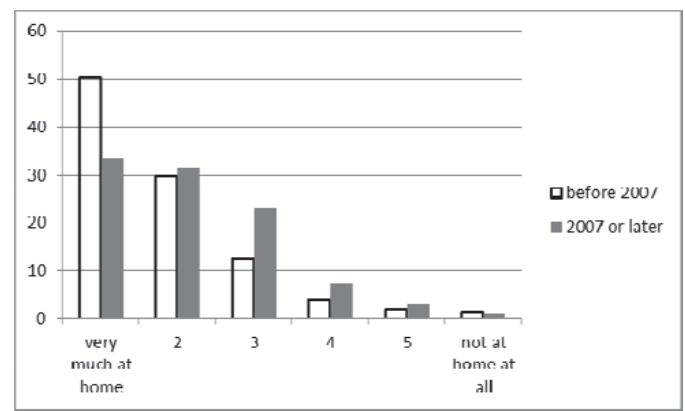

Figure 4: Q1.3xQ1.7: Duration of residence $x$ Feel at (valid percentage, $n=542$ )

As was the case in the summary data, the identification with the city increased significantly with the duration of residence, again without any significant difference in the effect between Germans and foreigners. Figure 4 again sets a cut point between residents since 2007 or earlier and maps these two groups against the "feel-at-home" categories from Figure 3. The difference is significant on a 99\% level.

\footnotetext{
${ }^{8}$ One may object that retirees do not work anywhere, however the value for the respondents indicating an age of $18-60$ is also only $36.5 \%$.

${ }^{9}$ Caveat: Since a sub-representative fraction of foreigners responded (cf. Section 1.2), one may surmise that primarily the well-integrated foreigners responded. One may further surmise that once foreigners integrate and participate politically - for instance answer questionnaires from the Municipality - they identify with their city as well as the German population.
} 


\subsection{Declared Participation in Elections - Attitude}

Questions 2.7 to 2.13 asked respondents whether they participated in various elections. It is clearly discernible to see that voter turnout as reported by far exceed the real one (Figure 5); the differences are of course statistically significant. Considering Figure 5, two explanations are possible: An overdeclaration to give the socially "desired" answer ${ }^{10}$ or a real bias in the respondents' sample. At this stage, the question cannot be answered.

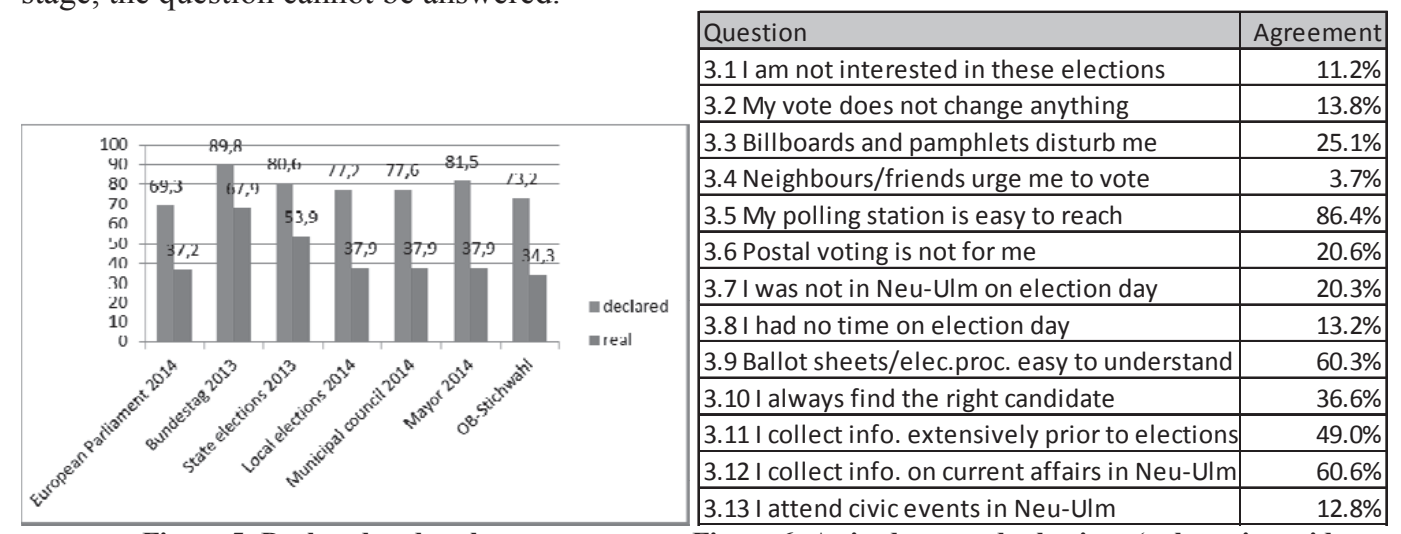

Figure 5: Declared and real turnout Figure 6: Attitude towards elections (only main residents, Germans and foreigners)

The questions concerning the attitude of citizens towards elections in Figure 6 reveal an almost ideal state: Only a few respondents are not interested in elections or believe voting does not change anything, the polling station is believed to be close and only a fifth is not convinced by postal voting; people are interested in their local affairs. How could such a convinced and democratically active citizenry produce a voter turnout of one third? There are however some chords in minor: Two fifth do not understand the ballot sheet (well) and only one third finds the "right" candidate - in a sample, where by and large three quarters indicate to vote. Furthermore, there is a statistically strong relationship (significance level 99.9\%) between (declared) voting and the answer to whether the respondent finds the right candidate (ie, participants rather tend to find the right candidate). This would indicate that the huge differences in Figure 5 are a real bias - not a socially motivated overdeclaration.

The conclusion can only be that neither elections nor this questionnaire (nor presumably any other municipal political activity) has reached the disenfranchised, the frustrated or the (at least at this stage) non-voters. Whoever, whether established party or new-comer, manages to tap into this huge voter reservoir motivating the disenfranchised to go to elections, can potentially unleash a major political move.

\footnotetext{
${ }^{10}$ Note that data was collected via anonymous questionnaires and not in interviews.
} 


\section{Factors Influencing the Motivation to Vote}

\subsection{Method Used}

In contrast to the summary analysis, individual data is available in this study to relate (declared) voting behaviour to the above factors in a meaningful way. The following constraints have to be met: (i) there is a dichotomous variable (declared voter/non-voter) influenced by some factors; (ii) a causal relationship rather than a mere correlation is required with the dichotomous variable as dependent; (iii) ordinal (possibly dichotomous) independent variables, no metric ones; (iv) a sample of approx. 800 and (v) a bias in some independents. To minimize statistical bias due to the low portion of foreigners in the sample, the following analyses are carried out for the German population only.

We selected a logistic regression with binary dependent [8]; For model refinement backward elimination was selected and the goodness of fit was tested according to Hosmer-Lemeshow [9]. The analysis was carried out in SPSS ${ }^{\mathrm{TM}}$. Several models were tested essentially confirming earlier results, such as the non-influence of age, the central importance of the residence time and the perceived importance of an election (the latter two both positively influencing turnout). We find that two models produce the most interesting results.

\subsection{Factors Influencing Feeling at Home}

The dependent was based on Question 1.7 (6-point Likert scale) in binary encoding (1 and 2 encoded as "feels at home", 4 to 6 as "does not feel at home"). In this encoding, $76.6 \%$ of the respondents were ranked as "feels at home". The independents selected were Questions 1.6 (children in Neu-Ulm, binary), Question 1.8 (spending work time, leisure during the week and at weekends in Neu-Ulm, all three binary) and again age and duration of residence.

The test was run in a four-stage backward elimination and the last iteration produced a very good goodness of fit (57.7\%). The iterations are shown in the original output in Figure 7 (in German). Three variables remained in the final model: Children in the city (KINDER), duration of residence (binary encoded before and from 2007, LEBTSEIT_BINAER) and age (ALTER). Both leisure and the work place variables were eliminated. Above all, the amount of leisure time spent in the city which is rather high (see 2.2) - does not influence the feeling at home. Backward elimination was stopped at 0.05 .

The leisure time spent in the city - which is substantially more than work time - obviously does not create a stronger link to the city. This is remarkable and may point to deficiencies in this regard. Apart from duration of residence and (closely related) age, it is only the fact that the respondent has children in the city that determines the feeling to be at home. 


\begin{tabular}{|ll|r|r|r|r|}
\multicolumn{7}{|c|}{ Modellieren, wenn Term entfernt } \\
Variable & & $\begin{array}{c}\text { Log- } \\
\text { Likelihood } \\
\text { des Modells }\end{array}$ & $\begin{array}{c}\text { Änderung der } \\
-2 \text { Log- } \\
\text { Likelihood }\end{array}$ & \multicolumn{1}{c|}{ df } & $\begin{array}{c}\text { Signifikanz } \\
\text { der Änderung }\end{array}$ \\
\hline Schritt 1 & KINDER & $-233,457$ & 9,028 & 1 &, 003 \\
& AZ_IN_NEUULM & $-229,061$ &, 238 & 1 &, 626 \\
& FZ_IN_NEUULM & $-229,010$ &, 134 & 1 &, 714 \\
& WE_IN_NEUULM & $-228,988$ &, 090 & 1 &, 764 \\
& LEBTSEIT_BINAER & $-231,425$ & 4,965 & 1 &, 026 \\
& ALTER & $-245,817$ & 33,750 & 4 &, 000 \\
Schritt 2 & KINDER & $-233,475$ & 8,974 & 1 &, 003 \\
& AZ_IN_NEUULM & $-229,143$ &, 310 & 1 &, 577 \\
& FZ_IN_NEUULM & $-229,033$ &, 091 & 1 &, 763 \\
& LEBTSEIT_BINAER & $-231,526$ & 5,076 & 1 &, 024 \\
& ALTER & $-245,818$ & 33,661 & 4 &, 000 \\
Schritt 3 3 & KINDER & $-233,517$ & 8,967 & 1 &, 003 \\
& AZ_IN_NEUULM & $-229,174$ &, 283 & 1 &, 595 \\
& LEBTSEIT_BINAER & $-231,550$ & 5,034 & 1 &, 025 \\
& ALTER & $-246,586$ & 35,105 & 4 &, 000 \\
Schritt 4 & KINDER & $-233,540$ & 8,732 & 1 &, 003 \\
& LEBTSEIT_BINAER & $-231,962$ & 5,576 & 1 &, 018 \\
& ALTER & $-253,454$ & 48,560 & 4 &, 000 \\
\hline
\end{tabular}

Figure 7: Backward elimination, influence on "feel-at-home"

\subsection{Factors Influencing Turnout}

Exploring the (declared) participation in the last municipal election 2014 (Question 2.11, n=747 valid responses, 78.4\% voted, German main residents only), several models are possible and were tested. In the following we would like to present the model we believe to provide the highest explanatory power. The independents selected were

- $\quad$ The duration of residence (binary before and from 2007, LEBTSEIT_BINAER);

- $\quad$ "My vote does not change anything (binary, AENDERT NICHTS);

- "I always find the right candidate" (binary, KANDIDAT);

- $\quad$ Kids in Neu-Ulm (binary, KINDER);

- "Polling station not easily reachable" (binary, LOKALNICHTERREICHBAR);

- $\quad$ "Postal voting is not for me (binary, BRIEFWAHLNICHTS);

- "I feel at home in Neu-Ulm" (binary, ZUHAUSE_BINAER);

Age and other variables were not included, as they already showed to have low explanatory power of voting behaviour. Again the backward elimination procedure was stopped at 0.05 . Figure 8 shows the backward elimination of the model, the Hosmer-Lemeshow test yielded $69.5 \%$ at the final stage, which is a fair goodness of fit. The result is revealing. Children in town, the feeling at home, even the duration of residence which was highly significant in the summary analysis and the bilateral tests with voter participation were all excluded. 
The feeling that the vote does not change anything and the lack of a suitable candidate were the main drivers of the voter participation (negative, ie, higher feeling of disenfranchisement leads to lower probability of participation). Only reluctance to use postal voting did make it to the last batch of variables. However, one may note that the duration of residence was cut only in the last step.

\begin{tabular}{|c|c|c|c|c|c|}
\hline \multicolumn{6}{|c|}{ Modellieren, wenn Term entfernt } \\
\hline \multicolumn{2}{|l|}{ Variable } & $\begin{array}{c}\text { Log- } \\
\text { Likelihood } \\
\text { des Modells }\end{array}$ & $\begin{array}{c}\text { Änderung der } \\
-2 \text { Log- } \\
\text { Likelihood }\end{array}$ & df & $\begin{array}{l}\text { Signifikanz } \\
\text { der Änderung }\end{array}$ \\
\hline \multirow[t]{7}{*}{ Schritt 1} & LEBTSEIT_BINAER & $-162,373$ & 1,543 & 1 & .214 \\
\hline & AENDERT_NICHTS & $-176,002$ & 28,800 & 1 &, 000 \\
\hline & KANDIDAT & $-170,865$ & 18,526 & 1 & .000 \\
\hline & KINDER & $-162,303$ & 1,402 & 1 & .236 \\
\hline & $\begin{array}{l}\text { LOKALNICHTERREICHB } \\
\text { AR }\end{array}$ & $-161,635$ &, 066 & 1 & .797 \\
\hline & BRIEFWAHLNICHTS & $-163,849$ & 4,494 & 1 & .034 \\
\hline & ZUHAUSE_BINAER & $-162,672$ & 2,140 & 1 & .144 \\
\hline \multirow[t]{6}{*}{ Schritt 2} & LEBTSEIT_BINAER & $-162,384$ & 1,499 & 1 & .221 \\
\hline & AENDERT_NICHTS & $-176,347$ & 29,424 & 1 &, 000 \\
\hline & KANDIDAT & $-171,622$ & 19,975 & 1 & .000 \\
\hline & KINDER & $-162,345$ & 1,420 & 1 & .233 \\
\hline & BRIEFWAHLNICHTS & $-163,861$ & 4,453 & 1 & .035 \\
\hline & ZUHAUSE_BINAER & $-162,695$ & 2,120 & 1 & .145 \\
\hline \multirow[t]{5}{*}{ Schritt 3} & LEBTSEIT_BINAER & $-163,528$ & 2,367 & 1 & .124 \\
\hline & AENDERT_NICHTS & $-177,720$ & 30,749 & 1 &, 000 \\
\hline & KANDIDAT & $-172,076$ & 19,461 & 1 &, 000 \\
\hline & BRIEFWAHLNICHTS & $-164,581$ & 4,473 & 1 & .034 \\
\hline & ZUHAUSE_BINAER & $-163,210$ & 1,731 & 1 & .188 \\
\hline \multirow[t]{4}{*}{ Schritt 4} & LEBTSEIT_BINAER & $-163,961$ & 1,501 & 1 & .220 \\
\hline & AENDERT_NICHTS & $-178,643$ & 30,865 & 1 &, 000 \\
\hline & KANDIDAT & $-173,547$ & 20,673 & 1 &, 000 \\
\hline & BRIEFWAHLNICHTS & $-165,298$ & 4,176 & 1 & 041 \\
\hline \multirow[t]{3}{*}{ Schritt 5} & AENDERT_NICHTS & $-186,527$ & 45,132 & 1 &, 000 \\
\hline & KANDIDAT & $-173,572$ & 19,222 & 1 &, 000 \\
\hline & BRIEFWAHLNICHTS & $-166,856$ & 5,789 & 1 & .016 \\
\hline
\end{tabular}

Figure 8: Backward elimination, general model

However, the fact that the feeling at home variable was eliminated as well raises the question, whether this is something specific to Neu-Ulm and its political environment or a general problem. To test this, the same model was run with the (declared) participation in the Bundestag Election 2013. The Hosmer-Lemeshow value indicates a rather limited goodness of fit, 0.89 . However, under that caveat, the model yields a result very similar to the previous model with participation in the municipal elections 2014 as dependent: After a six-step elimination process, AENDERT_NICHTS and BRIEFWAHLNICHTS remain in the model, with significance levels of 0.000 and 0.047 , resp. (for space constraints depiction of the elimination process is omitted here). The lack of a suitable candidate (KANDIDAT) is not in the final model on the federal level (understandable, as the suitability of local election candidates will hardly play a role in federal turnout). Again the feeling at home (in Neu-Ulm) was not in the final model (eliminated in Step 4). It needs to be reemphasised that - due to the low portion of foreigners in the sample - the analyses in Section 3 were carried out among Germans only.

This result enables one to conclude that the political disenfranchisement does influence the municipal turnout - however said disenfranchisement is not limited to the municipality. It is rather a general influencing factor that drives down turnout. Hence, it remains to be determined how far activating measures taken on the municipal level do actually increase turnout in the face of a clearly 
general disenfranchisement. The general results would support both Rosenstone and Hansen [7] in that mobilization is key as well as Verba et al. [3] in their resource-based view on turnout concerning postal voting.

\section{Summary}

From the statistical findings one may conclude:

- More attention could be paid to the specificities of EU foreigners (who are allowed to vote on the municipal elections), maybe to include EU foreigners to the major party lists; there is however no significant relationship between the property EU foreigner and "I always find the right candidate".

- The models in Section 3.3 tell a story of general political disenfranchisement as a main driver of voter (non-)participation; it remains doubtful, whether measures on the municipal level can change this general feeling. The results in Section 2.3 show that there is a large portion of non-voters, who once activated, may trigger major political change.

- The high fluctuation of (German!) residents is another main driver of low turnout which was shown both in the summary analysis in [1] and the individual questionnaire data; it crucially influences the feeling at home and - at least in the summary analysis - shows a high correlation with turnout.

Out of these three factors, two are difficult to "fix" on the municipal level. Neither can a general alienation to politics be fixed on the municipal level; nor can the high fluctuation in the town population, which it is rooted in the structure of the city (twin city with Ulm, highly active economy and educational institutions implying fluctuations in resident students). Hence, the options of the Municipality to address these issues unfortunately appear limited.

\section{References}

Web addresses checked as per March 28, 2017.

[1] BUllinger, A., PROSSER, A. and SCHENK, B.: Reasons for Low Voter Turnout - An Empirical Case Study in Neu-Ulm. In CEE e|Dem and e|Gov Days 2016, Hrsg. Alexander Balthasar, et al.: Budapest: OCG, 2016, pp. 579-588.

[2] KANUK, L. and BERENSON, C.: Mail Surveys and Response Rates: A Literature Review, Journal of Marketing Research Vol. 12, No. 4 (Nov., 1975), pp. 440-453, download from http://www.jstor.org/stable/3151093.

[3] VERBA, S. SCHLOZMANN, K.L. and BRADY, H.E.: Voice and Equality - Civic Voluntarism in American Politics, Harvard University Press, 1995.

[4] BARNES, S. H. and KASSE, M.: Political Action: Mass Participation in Five Western Democracies, Sage Publications, 1979. 
[5] NORRIS, P.: Conclusions: the growth of critical citizens and its consequences. In Norris, P. (Ed.), Critical Citizens: Global Support for Democratic Governance, Oxford University Press, 1999, pp. 257-272.

[6] VAN TUBERGEN, F. and KALMIJN, M.: Destination-language proficiency in crossnational perspective: a study of immigrant groups in nine Western countries, American Journal of Sociology, 110, 2005, pp. 1412-1457.

[7] ROSENSTONE, S.J. and HANSEN, J.M.: Mobilization, participation, and American democracy, MacMillan, 1993.

[8] ANDRESZ, H.-J., HAGENAARS, J.A. and KÜHNEL, S.: Analyse von Tabellen und kategorialen Daten, Springer, Berlin et al, 1997, S. $262 \mathrm{ff}$.

[9] HOSMER, D.W. and LEMESHOW, S.: Applied Logistic Regression, Wiley, New York, 2013.

\section{Annex: Questionnaire}

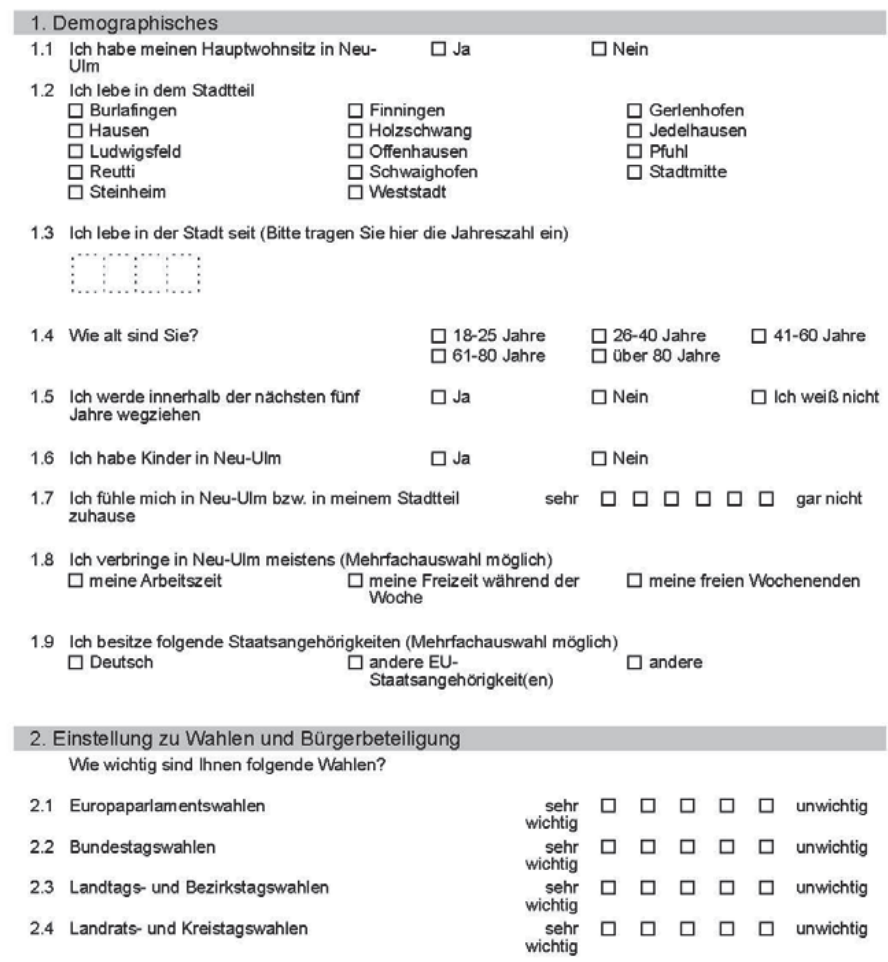




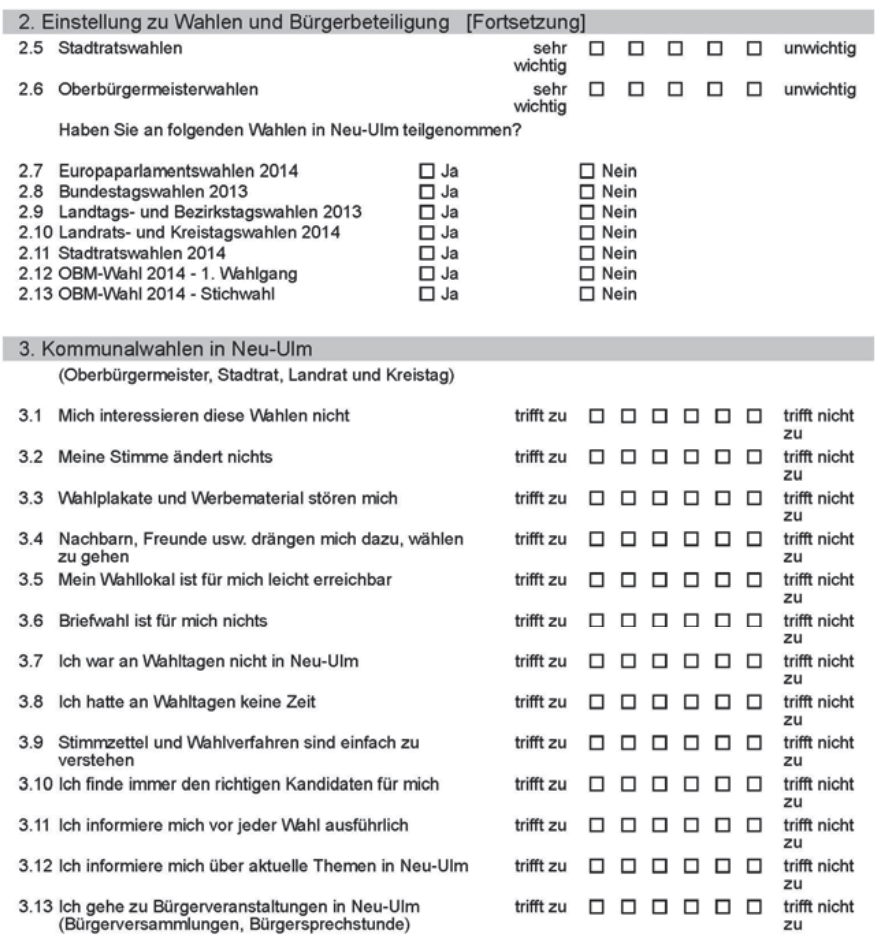

